\title{
Editorial
}

\section{Helen Beetham}

Consultant in Higher Education

[All references are to papers in this special edition unless stated otherwise]

This special edition of JLDHE focuses on the intersection of learning development with new practices of the digital age. On the one hand this might simply mean the 'ways in which digital technologies are used in the work of learning developers, academic teaching staff or other practitioners seeking to improve student learning' (JLDHE Call for Papers, Digital Technologies Special Edition, August 2014). Like all good, reflective practitioners, we embrace new technologies when they seem designed to help us do our work more effectively. We use screencasts to build learning resources (see Reid et al., this edition), and audio capture to give engaging feedback; social media to amplify our good advice, and productivity tools to manage our resources of time and professional energy.

On the other hand, the papers published here take a wider and deeper view of what is at stake. Even if we confine our attention to the technologies we use as professional developers and educators, these change the meaning of our practices, and - because our practices fundamentally concern this - our relationships with students. Whistance, for example, finds that blended feedback (spoken, written and signed content) is received by students as more personal, thoughtful, and actionable than written-only feedback, which at some point in the fairly recent past replaced in situ verbal feedback as the predominant mode. In their case study on open badges, Hole et al. point to the possibility that a wide range of development opportunities could in future be credentialised. In both cases we see that fairly simple tools for recording a learning process can be used to change its meaning and value.

Technologies are not just tools for performing particular tasks, but tools for thinking with, relating with, creating the settings for those relationships and performing our identities in the world. If we want to support students through the difficult business of coming to think, act and be different(ly), we will have to engage with (their specific engagements with) digital technologies. In what follows I explore how digital technologies have been implicated in changes both to formal modes of learning and to learners' informal practices 
on the border zone. I also consider how wider changes in the character of institutions are impacting on our professional practice and on our relationships with students. Finally, in gathering up some of the diverse threads of thinking in this special edition, I ask how we might move towards a more resilient stance in our own relationship with digital technologies in the context of our work as developers and educators.

To begin, it seems unarguable that learning in academic settings has changed profoundly in response to the ubiquitous use of digital technologies. Case studies in this edition describe students learning through online scenarios (Levin et al.), video feedback (Whistance) and virtual collaborations (Reedy and Goodfellow). Reeves' contribution looks at learning in the new subject areas of Digital Curation and Digital Sustainability. Other papers consider the whole enterprise of learning against a backdrop of transformation in academic ways of knowing and coming to know (Bainbridge, Thanaraj and Williams). Different fields of knowledge and practice have experienced different kinds and directions of stress, but there is not one field whose practitioners can carry on as if the internet never happened: as if their research methods, their relationships with colleagues, their publishing and communication practices, the public perceptions of their field, their professional identities and reputations and the learning habits of their students are the same as they ever were.

We know that many academic staff find these changes difficult: Thanaraj and Williams identify feelings of fear, anxiety and loss of identity (among other more positive responses). But surely students are at home in the brave new digital world? It is true that most students are confident users of their own devices and apps/services (though a much smaller number explore beyond the basic functions or can recover when things go wrong). But many if not most students struggle with formal, academic uses of digital technology. Academic digital spaces have different rules to Facebook or Instagram, for example about the acknowledgement of other people's material. They have different registers of communication and different criteria for judging the value of those messages. Access is carefully guarded and closely regulated through policies on copyright, plagiarism and fair/safe use, and through secure identity management which allows students' behaviour in academic spaces to be monitored (more on this later). Learners who have grown up with 'plug and play' devices and apps designed for 'frictionless adoption' can also find academic systems - those that correspond to complex practices such as CAD or reference management or data analysis - difficult to learn. We should not be surprised that students 
struggle to know what is expected of them or to inhabit these ways of digital being as their own: this is Lea and Street's academic literacies model played out in the digital arena (Lea and Street 2006). But educators themselves are not always certain how to behave in this arena, and unless we are confident enough to admit to these uncertainties, and/or committed to a pedagogy in which vulnerability and risk play a part, we may be less able to support students with their own identity work.

I find it interesting that both Almond and Bainbridge include discussions of 'difficulty' in their accounts of digital learning. When students in Almond's 'University Conversation' ask for learning to be accessible and 'fun', academics worry that this misses 'threshold concepts and troublesome knowledge, and the productive role of discomfort'. There is an old truism here - that learning requires the right kind of challenge - and one that acquires a new force at a time when the difficult process of self-transformation is being refigured in terms of learning 'experiences' to be consumed. What interests me is how Bainbridge brings technology into this picture. For him, the novelty of digital technology is distracting us from the difficulties of real learning, and at the same time estranging us from the natural and (face-to-face) social worlds where we experience the 'holding' that we need to encounter those difficulties with resilience.

There are echoes of this concern in the conversations I and other researchers have had with students under the umbrella of the Jisc 'digital student' project (Beetham and White 2014). Many students find digital technology a distraction from learning, at times. Most would rather have face-to-face contact with their tutors and peers than spend time in virtual spaces, however well-designed the setting or the materials. But there are many ways in which digital spaces do provide 'holding' to students who have grown up with technologies at hand. Mobile communications and social media allow them to feel connected with families and friends. Social life takes place in parallel online and offline spaces - as indeed does learning. Even signing on to institutional systems is an aspect of achieving an identity as a student, and students often form work patterns around specific IT facilities. Students also have powerful relationships with their own devices, and being encouraged to use these in class can make academic tasks seem less daunting. Rather than estranging students from more 'authentic' relationships, digital technologies can provide a sense of familiarity and belonging. 
To take on the other side of Bainbridge's argument, digital technologies can also provide challenges that are productive of authentic learning. Interviewed towards the end of their courses, students often recall specific encounters with technology that have been critical to their academic development. One common such experience is learning to use systems that - as I argued earlier - correspond with complex practices of the discipline such as data analysis, design, project management and problem solving. Another is the production of digital artefacts relevant to the field of study. These might be wiki pages or blogs, curated collections and digital narratives, coded apps, multimedia artefacts, research outputs and learning materials, e-portfolios. The meaning of these artefacts depends on whether they are collaboratively or individually produced, locally or publicly shared, whether they arise within a wider research/professional project, and whether or not they include personal material. But all have authentic value in the digital spaces of the subject or profession, and relative to students' aspirations.

So if technology can alienate us, it can also (with the right educational intention) be used to release our creative and productive energies and for identity work. I would tentatively relate this observation to Heidegger's distinction between the condition of humanity in modern technological systems - which he understood to subsume human reason to their own instrumentality - and our 'proper' relation to technology as a creative revealing or bringing forth of human potential (techne-as-poesis) (see e.g. Holden 2009, Nadal 2010).

These changes in formal learning are relatively well known to teaching staff, even if they do not wholeheartedly embrace them. Another set of changes has taken place on what I described as the 'border zone' between formal academic and informal learning. Despite our intensive monitoring of their behaviours and experiences, students still spend much of their study time in their own spaces: reading, annotating, collating, marking references and leaving traces, note-making (whatever that means to them), sharing ideas, making judgements about content and context, supporting each other, pursuing interests and offering up what interests them to others, writing, drawing and creating other kinds of representation, solving problems, managing (more or less successfully) their time, tasks and attention. These are lifelong habits for which the vast majority of students use digital technology as a context and a means of support.

In Whistance's case study on the use of video to record and give feedback on sign language, I have already suggested that video capture changes the meaning of students' 
performances as learning events. With mobile devices, the potential to capture learning as it happens is always ready-to-hand. In fact, many of today's students do not know what it is to perform in an unrecorded/unrecordable space, unless a teacher or developer explicitly creates that space by asking for mobile devices to be put away. The habit of constant selfrecording and self-reporting is of great potential value in learning development. It allows for a closer relationship between informal practice and the kinds of reflection, review and conscious self-development that we want to encourage in learners. Not many learners will develop those habits for themselves, however. So in our conversations with them, we are not only helping to clarify what is expected in the academic digital space (and dealing with that as a site of contestation and change), we are also hoping to support 'good', reflective habits in their own use of digital technologies and in their personal digital spaces - without necessarily following them there.

These two kinds of digital practice can of course be in tension with one another, leading to concerns about plagiarism, about legitimate vs illegitimate sharing between students, about academic forms of expression vs social media norms, around issues of provenance and the ownership of students' ideas and data. Again, as developers we are used to this border zone being a site of difficulty for learners - of contested meanings and identities but we may be less used to navigating it as a specifically digital space.

For some students the digital space does introduce new and unhelpful kinds of difficulty. This is especially true for those who have had little - or mainly negative - experience of using technology for learning in the past. Thoughtfully applied, though, digital technologies can scaffold students' access to academic ways of thinking and being, as case studies in this edition show. An example I often use in my own work is social bookmarking, which helps students to define an academic space through simple practices of linking and annotating, and offers a bridge between social and academic norms for acknowledging that other people have interesting things to say.

This brings me to a third area of intersection, between digital technologies and academic institutions. Reeves draws attention to the fact that our practices are situated in specific and structural ways: how we relate to learners and their development depends on the institutions we inhabit. In 2014 those institutions are inherently digital organisations, reliant on digital systems for all of their core functions, and increasingly valued against metrics that can only be established through the use of digital data at scale: KIS, DELHE, NSS 
scores and so on. The institutional systems I mentioned earlier as giving students a sense of belonging also of course subject them to constant monitoring of their online behaviours. 'The structural features of universities as organisations continue to drift towards the bureaucratic, requiring extensive tracking and regulation' notes Nick Almond (citing Brown, 2004). Digital technologies do not dictate such practices but they certainly support them. When the value of our work with students is expressed as a function of these data-derived metrics, we may well agree with Bainbridge that digital technologies have been fetishised, and we may even exhibit some of the resistant behaviours that Thanaraj and Williams observe among teaching staff.

Ironically, though, our organisations are also forced to define their role and assert their value in direct contrast with the digital alternatives. One of the most obvious advantages of a 'traditional' degree programme over those alternatives - open badges, open courses, open journals, wikipedia, online interest groups, TED talks, youtube and the Kahn academy, to name only a few - is the availability of academic developers and other professionals with responsibilities for student learning. Reid et al. see a rise in demand for learning development services as the result of students exercising this advantage. Reedy and Goodfellow are more inclined to ask how support can be embedded into courses of study. They remind us of the requirement placed on universities by Dearing (NCIHE 1997), and reinforced by successive governments since, to support students' general development alongside their grasp of subject matter. Digital and information literacies are now, in their view, central to what a modern university should offer, but only as part of their more general responsibility for students' thriving in and beyond their studies.

So while cuts to services make learning development work vulnerable, and pressures on teaching staff make it ever more difficult to provide each student with the safe holding, the nurturing and the appropriate challenges that they need, nevertheless this work has never been more important. The QAA has this month announced that digital capability will be one of its two review themes for 2015-16 (QAA 2014). Institutions are about to be assessed on how effectively they prepare students to thrive in a digital world. What would it look like if we were doing this well? How do we develop resilience in our own relationship to digital technologies, so that we can provide safe spaces for students to do the same?

Perhaps it could be part of our role, as we support students' developing digital practices, to help them become not just good consumers of digital media and product, but creative 
producers and critical actors as well. Perhaps we could help them to question the ends for which digital technologies offer themselves so easily as the means. Questions learners can be encouraged to ask in relation to any new device or service could include: How does this help me to express my ideas? How is it shaping the world for me and for others? How will it allow me to act in accordance with my values and how will it sustain the life I want to lead? Learning activities such as investigating the life of digital goods - their raw materials, manufacture, marketing and disposal - encourage deeper thinking about what it means to live in digital world. Building wiki pages or developing multi-media materials give students new insight into how digital messages are constructed and have their effects. We need to critique the role of technologies in learning and to claim digital tools creatively (and selectively) for our own practice, but this should be in the service of our work with learners, which should focus on developing their own repertoire of digital practices and their capacity for informed critique. This ties in with the work of Hall et al. (2014, cited by Reedy and Goodfellow in their article), whose recent review of digital literacy frameworks concluded that 'criticality' rather than technical competence is key.

Digital technologies mark out a new landscape in which the work of development takes place, not a utopian one certainly, but not one devoid of light. Technologies offer new ways of nurturing, reassuring and 'holding' students in the difficult work of learning and development, particularly students for whom the digital route is the only or the most supportive way of accessing opportunity. Technologies also usher in new forms of alienation, commodification and - for less digitally confident students - of difficulty. They promise to level out inequalities of access but at the same time they amplify inequalities of learning capital, especially as 'bring your own' (device, software, attitude, capability) becomes the norm. We need to understand these interactions in all their complexity and specificity, both at the structural level of organisations, disciplines and knowledge practices, and at the human level of learners and their identity work. The papers in this special edition begin to map out that space.

\section{References}

Beetham, H. and White, D. (2014). Digital Student: students' expectations and experiences of the digital environment. Jisc. Available online at: http://digitalstudent.jiscinvolve.org/wp/ (accessed 12 November 2014). 
Brown, R. (2004). Quality assurance in higher education: The UK experience since 1992. Psychology Press.

Hall, R., Atkins, L. and Fraser, J. (2014). Defining a self-evaluation digital literacy framework for secondary educators: the DigiLit Leicester project. Research in Learning Technology Vol. 22, 2014

Holden, J. (2009). Heidegger, Writing, and Technology. Writing Technologies Vol. 2, No. 2.

Lea, M.R. and Street, B.V. (2006). Theory into practice. London: Taylor \& Francis.

Nadal, P. (2010). Heidegger's Critique of Modern Technology: On "The Question Concerning Technology". Available online at: https://belate.wordpress.com/2010/07/12/heidegger-modern-technology (accessed 12 November 2014).

NCIHE (1997). Higher education in the learning society. Report of the National Committee of Inquiry into Higher Education: The Dearing Report. London:HMSO.

Quality Assurance Agency (2014). Higher Education Review: Themes for 2015-16.

Available online at: http://www.qaa.ac.uk/en/Publications/Documents/HER-ThemesGuidance-15-16.pdf (accessed 12 November 2014).

\section{Author details}

Helen Beetham is a researcher, writer and adviser on e-learning in higher education. She has worked as a consultant to Jisc since 2004 and in that capacity produced influential reports on topics as diverse as curriculum design, e-portfolios, open educational practice and digital literacy. Her chapters and edited volumes (e.g. Rethinking Pedagogy for a Digital Age, Routledge 2013) are set texts on many postgraduate courses in education. A regular keynote speaker and guest lecturer, she has advised more than 30 universities on digital education issues, including most recently under the HEA Changing the Learning Landscapes programme. She is currently writing up a study into the experiences of digital students. 